It is delivered in a relaxed and informal environment. The sessions encourage discussion, strengthen working relationships, break down boundaries across different aspects of the organisation, share experiences, improve morale, improve health and well-being and provide exposure to different subjects.

Aim To provide all staff across the organisation an opportunity to acquire new information and knowledge for professional and personal development.

Where possible, we choose topics to match local and national awareness days.

These sessions provide presentation experience opportunities, utilise hidden staff skills and engage local service providers. The sessions also provide a forum to share news and celebrate events. Recent topics have included:

- What is social media?

- Skin cancer awareness

- Eating salt

- Walk to the park

- Sharing stories

- Desert island discs - music reflection

- Mindfulness

- Laughter therapy

- Recording your learning

- Choices after death from a local funeral director.

Future topics include flower arranging, computer skills and continuing professional development sessions.

Evaluation and sustainability Feedback suggests the sessions are appreciated, useful and informative. Sessions are varied and interesting. Staff are encouraged to suggest topics. Directors are supportive and encouraging of staff attendance to these sessions. Staff can attend without guilt. Given numerous part time staff, we will trial alternating days to be more inclusive. Clinical training now stays in clinical areas.

All sessions incur no cost as all external speakers provide their services free of charge.

\section{P-238 A CROSS- ORGANISATIONAL APPROACH TO EDUCATION IN PALLIATIVE AND END OF LIFE CARE}

${ }^{1}$ Anna MacPherson, ${ }^{2}$ Jeanette Shepherd. 'East Lancashire Hospitals NHS Trust, Burnley, UK; ${ }^{2}$ Pendleside Hospice, Burnley, UK

\subsection{6/bmjspcare-2016-001245.259}

Context Increasing access to appropriate education and training in palliative and end-of-life care are widely recommended to improve patient care. Coordinating and delivering an up-to-date education programme to meet the needs of varied health and social care professionals takes significant time and resources. We decided to approach this from a locality perspective, aiming to make the most effective use of all resources available.

What is being done? All relevant local organisations agreed to be involved, including hospices, acute trust, community service providers, clinical commissioning groups and social care.

An overall strategy was developed following local consultation, and an action plan developed:
1 - Scope available resources and compile and publicise a training directory

2 - Look for urgent gaps in training and how they may be filled

3 - Develop a competency framework covering health and social care

4 - Map the competency framework to the training directory and ensure a fully rounded programme is in place

5 - Incentivise attendance at training.

Progress and outcomes

- A training directory has been developed, and its impact being measured by monitoring subsequent access to training

- Urgent gaps identified:

- Training in primary care on DNACPR and care in the last days of life. Locality based sessions held, attended by over 80 GPs; well-evaluated and well-attended

- Communication skills training - a coordinated programme is being developed, using trainers from each major provider

- A competency framework has just been developed and organisations are starting to link to appraisal and PDR processes

- Liaison is taking place around contract requirements for care homes to include attendance at training

Sustainability Training being planned is cost neutral. Initiatives have needed time investment, but are reducing duplication and coordinating work better between organisations.

This model and approach has been effective, and could easily be duplicated.

\section{P-239 TOMORROW'S CARERS - HELPING TO UNLOCK THEIR POTENTIAL!}

Tricia Wilcocks, Sue Marshall. ellenor, Gravesend, UK

10.1136/bmjspcare-2016-001245.260

Background The hospice identified previous work placements offered internally provided an inconsistency of experience for learners, with multiple requests placing a burden on care staff, resulting in a review of the model of student support. This closely related to influential factors for future work force planning as follows: increasing demand on health and social care services; growing role of hospices as educators; a need to influence student career choices as early as possible; reluctance to expose young people to direct care.

To extend opportunities, funding was obtained from Health Education England to trial different models of support.

Aims

- Increase number of students experiencing hospice care

- Provide alternative structured training models

- Provide consistent positive experience of care delivery

- Support workforce to stimulate student's experiences.

Approach Comparison of two supported training models:

1. One week accredited course

2. Six month placement. 


\begin{tabular}{|c|c|c|}
\hline & 1) Accredited course & 2) Placement option \\
\hline Duration & One week full time & $\begin{array}{l}\text { - Two induction days } \\
\text { - One evening per week for six } \\
\text { months }\end{array}$ \\
\hline Staff resource & Two facilitators - full time & $\begin{array}{l}\text { - Induction facilitator } \\
\text { - Mentor - providing observations } \\
\text { in practice }\end{array}$ \\
\hline $\begin{array}{l}\text { Maximum yearly } \\
\text { capacity }\end{array}$ & 24 & 28 \\
\hline Activities & $\begin{array}{l}\text { - Interview multi-professional } \\
\text { staff } \\
\text { - Engage with patients in day } \\
\text { therapy }\end{array}$ & $\begin{array}{l}\text { - Shadow ward staff } \\
\text { - Interact with patients on ward }\end{array}$ \\
\hline $\begin{array}{l}\text { Potential } \\
\text { qualifications }\end{array}$ & $\begin{array}{l}\text { City and Guilds: } \\
\text { 1) Employability } \\
\text { 2) Understand social care } \\
\text { 3) Awareness of end-of-life } \\
\text { care }\end{array}$ & 1) Care certificate \\
\hline
\end{tabular}

A student's conclusion - "I was relieved to find out we were being taught valuable skills on an actual course, not just making teas.”

Conclusion From successful pilot, we expect the following outcomes to shape future training:

- Increase in students accessing and considering a career in care

- Identify best approach to support students

- Portable qualifications achieved

- Focused opportunity for staff to support students.

\section{P-240 PEOPLE, PARTNERSHIPS AND POTENTIAL - A COLLABORATIVE TEACHING PROJECT BETWEEN CYPRUS AND A UK HOSPICE}

Caroline Archibald, Faith Rylands, Kate Shorthose, Maxine Smith. St Margaret's Hospice, Taunton, UK

\subsection{6/bmjspcare-2016-001245.261}

Introduction In 2015 in Cyprus a family member became unwell and needed medical assistance, which led to a palliative care nurse crossing paths with a Cypriot Hospice.

An extended invitation to come and visit the hospice, meet the staff and talk about the role of a palliative care nurse working in the UK. This resulted in a request to develop formalised education programme and to return to Cyprus to provide teaching on end-of-life issues, communication and symptom control. This has resulted in ongoing teaching collaboration.

Aims

- To offer training to the multidisciplinary team on end of life issues, communication and symptom control issues through modelling, sharing skills and knowledge

- Sharing good practice

- Offering peer support

- Sharing our experiences with staff and volunteers working at a Cypriot hospice and within our own UK hospice

- Empowering the Cypriot nurses through up to date knowledge on issues in palliative care.

Method

- Communication via skype and regular email contact
- A fact finding mission

- Delivery of tailored teaching programmes on end of life issues, communication and symptom control issues to the hospice nurses and doctors in Cyprus

- Two Cypriot nurses released to shadow colleagues working in the UK hospice. They will then cascade the knowledge, skills and experience they have gained when they return to Cyprus.

Conclusion

- Positive feedback from the doctors and nurses on the benefits of the teaching and impact on care delivery

- A rolling rota planned for the Cypriot nurses to come over and gain experience of working alongside our nurses

- Ongoing collaboration between the two hospices

- Awareness and respect for the cultural and economic differences in end-of-life care delivery

- Learning and sharing of experience for UK nurses of the challenges within other healthcare settings.

\section{P-241 FOUNDATION DOCTORS EXPERIENCES OF DISCUSSING CPR}

${ }^{1}$ Alexandra Hadjimichalis, ${ }^{1,2}$ Pauline Dand. ${ }^{1}$ East Kent University Hospitals Foundation Trust, Kent, UK; ${ }^{2}$ Pilgrims Hospices, Kent, UK

\subsection{6/bmjspcare-2016-001245.262}

Background Appropriate, anticipatory cardiopulmonary resuscitation (CPR) discussions and decisions are now an integral part of good clinical practice, and have been shown to reduce futile treatment and end-of-life distress.

CPR decisions have been established to rest with the most senior clinician, yet our hospital experience suggests that even the most junior of doctors can be involved in this process. For doctors in training this can represent one of the most difficult ethico-legal challenges they face, with reports of lack of confidence and formal teaching.

Aims The aim of the study was to explore our most junior doctors' - 'foundation doctors' - experiences of discussing CPR with hospital in-patients and their relatives; to identify any training needs, and if required design and deliver an appropriate training intervention.

Methods An electronic survey using a semi-structured questionnaire was distributed to 118 foundation doctors working in East Kent University Hospital Foundation Trust. Simple percentage analysis of results was undertaken.

Results Response rate to the questionnaire was $45 \%$. The majority of respondents did have experience of discussing CPR with patients/relatives, with 69\% [31/45] reporting initiating such a discussion. A third of these doctors felt inadequately prepared for such discussions ['not prepared' or only 'a little prepared']. Many found the discussion difficult [34/40] and nearly half [18/40] found it distressing to some degree. Only a minority [6/45] reported having received formal postgraduate teaching on conducting CPR discussions, and most respondents [39/45] reported a need for further training.

Conclusion The majority of foundation doctors in this study had been involved in conversations about CPR. A significant number felt inadequately prepared for the task and the majority identified specific teaching and training needs. The investigators have collaborated to design an educational initiative for local foundation doctors based on identified needs which is currently being piloted. 